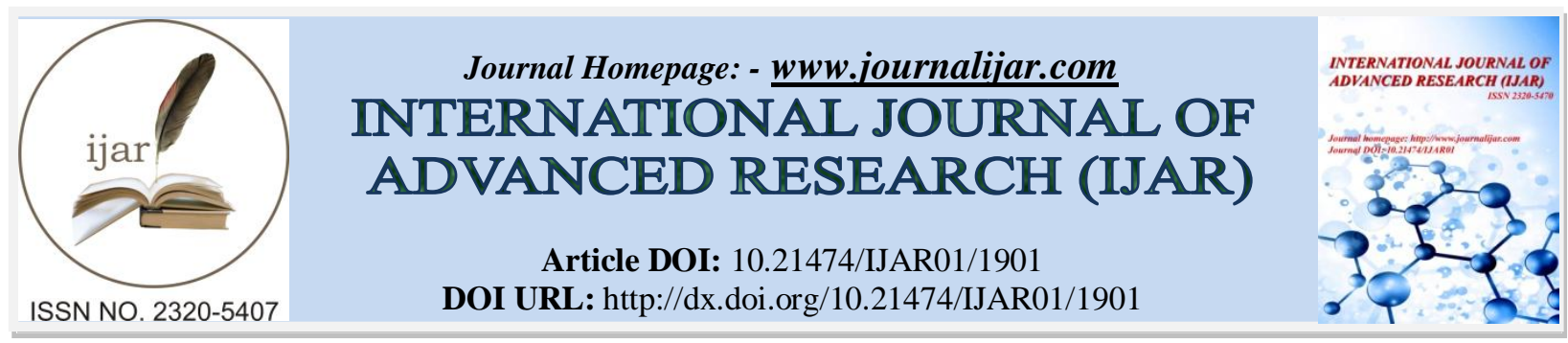

RESEARCH ARTICLE

\title{
MAPPING OF AVAILABILITY OF HOUSEHOLD AMENITIES TO MEASURE SOCIAL EXCLUSION IN HARYANA.
}

Virender Chhachhiya.

Research Scholar Kurukshetra University, Kurukshetra.

\section{Manuscript Info}

Manuscript History

Received: 16 August 2016

Final Accepted: 19 September 2016

Published: October 2016

\section{Abstract}

The present paper is an attempt to analyse the spatial variations in household amenities and assets in respect of availability of source drinking water, availability of lighting, latrine facilities and fuel used for cooking facilities in all 21 districts of Haryana. These amenities improve the quality of life and are the positive signs of social status and instruments for a better life. In the present study GIS techniques has been applied to show the spatial pattern. As per 2011 census, only $68.8 \%$ of households having facility of drinking water through tap, only $28.5 \%$ households using LPG as fuel in cooking, 9\% of households have no access to electricity, $31.4 \%$ of households having no access latrine facility. The study shows that the availability of tap as main source of drinking water decreases from high in the northern part to low in the Southern part of the state. There is a declining trend in availability of electricity from east to west direction. Some districts in southern part of the state, the general condition of latrine facilities is good in Haryana. There is a more than 50\% household using LPG in eastern side of the state but lower consumption have shown in western side of the state.

Copy Right, IJAR, 2016,. All rights reserved.

\section{Introduction:-}

The meanings of social exclusion "Exclusion" is not a concept rooted in the social sciences, but an empty box given by the French state to the social sciences in the late 1980s as a subject to study... The empty box has since been filled with a huge number of pages, treatises and pictures, in varying degrees academic, popular, original and valuable'. (Murard, 2002:41)

Housing and household amenities are basic needs of human beings as it provides protection from weather, place to bring up families and a place to work and also it is fundamental duty for government to provide affordable homes and housing amenities to everyone. Household assets and amenities reflect a household's quality of life. A lack of basic amenities has important implications for the quality of life of ordinary people and their health. The provision of basic services such as piped water, sanitation systems, and electricity has been an important goal of Indian developmental planning. Although there was progress in the supply of safe water, electricity and access to toilets to households, there were large variations in the pace of achievement of the goal (shaw, 2007). There is key dependencies exist between water supply and sanitation and improvements in health, education, population stabilization and overall human development (Dreze and Murthi, 2001; Gupta and Mitra, 2002). 
Electricity provides more reading and education; liquefied petroleum gas (LPG)/PNG fuels provide a cleaner environment and better health as well as reduces in time for cooking; clean water and sanitation reduce the prevalence many diseases; access to piped water reduces the time of women spend in water collection. These amenities improve the quality of life and are the positive signs of social status and instruments for a better life. According to Census of India "household is usually a group of persons who normally live together and take their meals from a common kitchen unless the exigencies of work prevent any of them from doing so. The term 'basic amenities', refers to drinking water supply, sanitation, electricity and so on (Shaw 2007). It is assumed that availability of drinking water, sanitation facilities, etc. might contribute to the health improvement of the people and determine the quality of life of the society (Nayar 1997). The lacking of these facilities or their insufficient availability in an area is not only exerting an impact on the health status of the population but also it has been due to the lack ofinefficiency of government. The health indicators such as availability of drinkingwater, sanitary facilities, etc, are much more required for health improvement among the population. Progress in sanitation and improved hygiene has greatly improved health, but many people still have no adequate means of disposing of their waste. This is carrying the risk of infectious disease, particularly to poor section of society..The present paper is an attempt to analyse the spatial variations and the level of development in terms of housing status and accessibility of household amenities and assets in respect of availability of source drinking water, availability of lighting, latrine facilities and fuel used for cooking etc. in all 21 districts of Haryana.

\section{Data and Methodology:-}

The present research work is based on secondary sources of data collected from the Census of India publication of 2011 on houses and household amenities of Haryana. In this study, houses and household amenities like percentage of household's population having facilities of drinking water, electricity, latrine and fuel used for cooking taken into account to spatial variation at the district level.

A set of indicators includes source of drinking water through tap, electricity, toilet facility and LPG used for cooking. In the first step, the raw data for each variable which determines the areal variation of levels of housing and modern household amenities have been computed, tabulated and analysed.

Arc GIS software (Version 9.3) has been applied to show the mapping of spatial patterns of houses and household amenities among the districts.

\section{Study Area:-}

The state of Haryana was carved out of the composite state of Punjab on the 1st November, 1966. Haryana is the 16th largest state of India and is stretched over an area of 44,212 sq. km. The state of Haryana is confine between $27^{\circ} 39^{\prime} \mathrm{N}$ to $30^{\circ} 35^{\prime} \mathrm{N}$ Latitude and $74^{\circ} 28^{\prime}$ to $77^{\circ} 36^{\prime} \mathrm{E}$ Longitude. The altitude of Haryana varies Between 700 to $3600 \mathrm{ft}$ above sea level. The total population of this state, as per the census report, 2011, is 25,353,081 with a population density of 573.4 per sq. $\mathrm{km}$. There are $65.21 \%$ of Haryana population lives in rural areas and $34.79 \%$ lives in urban areas. The Percentage of Urban Population increased from 28.92 per cent in 2001 to 34.79 per cent in 2011, registering a net gain of 5.87 per cent. Sex Ratio of Haryana increased to 877 in 2011 in comparison to 861 of 2001, a net gain of 16. In Rural areas, Sex Ratio increased to 880 in 2011 from 866 of 2001. In Urban areas, Sex Ratio increased to 871 in 2011, from 847 in 2001 registering a net increase of 24.

\section{Results and Discussion:- Drinking Water:-}

Safe water refers to water supplied from covered sources such as through taps, tube wells and hand pumps. Water from uncovered or exposed sources such as wells, springs, rivers, tanks and ponds are not considered safe. The source for drinking water identified by the Census 2011 include tap, hand pump, tube well, tank and pond, river and canal, spring and any other source for drinking water at the time of house listing operations. As per Census 2011, $68.8 \%$ of the total households have tap water as the main source of drinking water. The highest proportion of households having source of drinking water is observed in Ambala (84.3\%) followed by Yamunanagar (83.3\%), Sirsa $(81.8 \%)$,Kurukshetra (80.4\%) and Gurgaon (80.2\%). The lowest is noticed in Mewat (23.4\%) followed byMahendergarh (47.7\%), Jind (49\%), Bhiwani (53.2\%) and Palwal (56.9\%). It is remarkable that exceptMewat, all districts in Haryana have recorded higher percentage than the nation average of the country(46.6\%) in Census 2011. It can be seen that there is a great variation in availability of drinking water among thedistricts of Haryana. An examination of spatial distribution of map given reveals that thereis also great variation in respect of source of drinking water through tap for population in the study area which shows the socially excluded districts. 


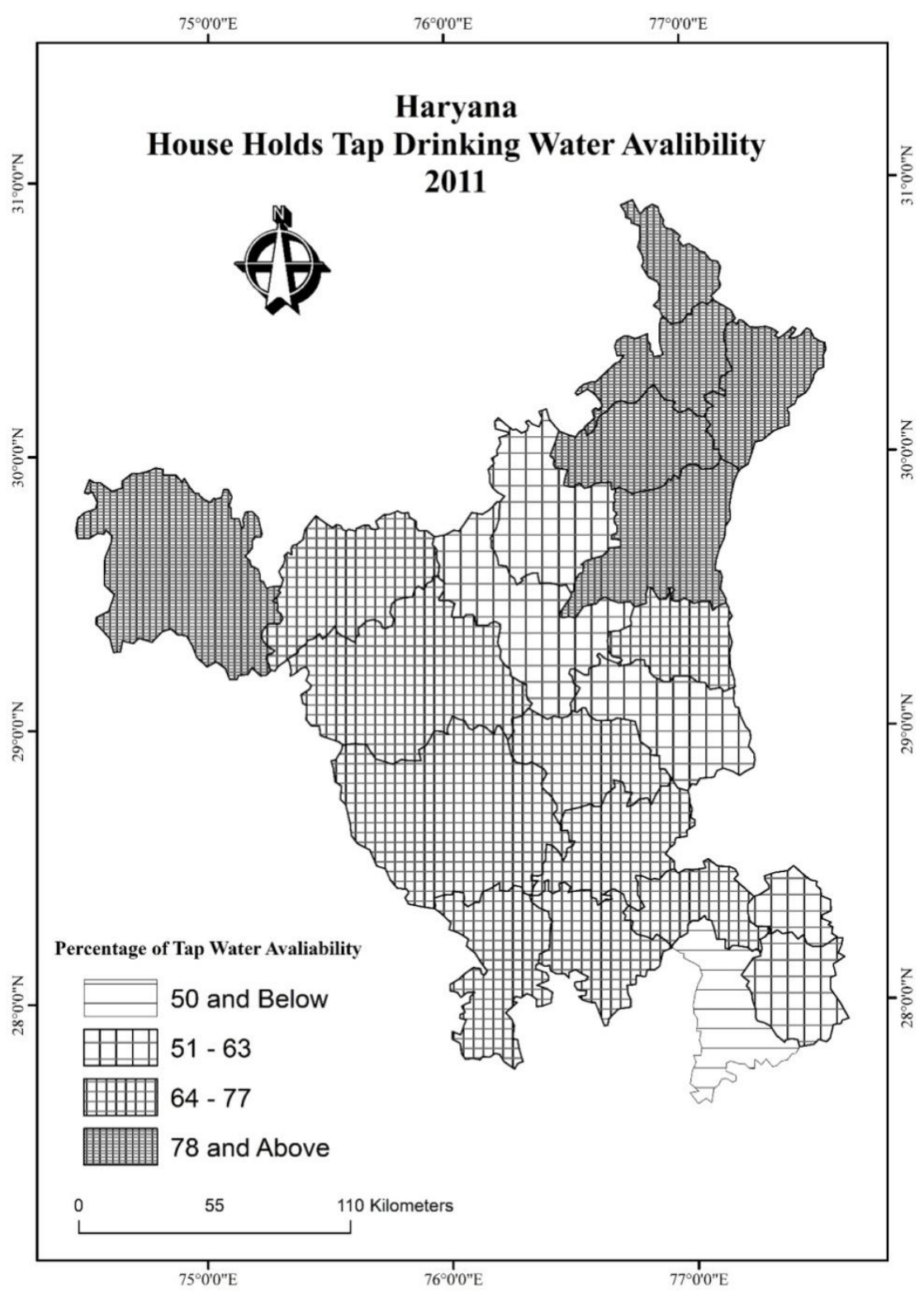

Availability of Electricity:-

During Census 2011, the information on source of lighting for the households have been collected under the classification of Electricity, Kerosene, Solar energy, other oil, any other and No lighting. Among the total households of 47,17,954 in Haryana, 42,70,297 (90.5\%) have electricity as a main source of lighting. The position of Haryana is much better than the national average as it is only $67.2 \%$ in 2011 Census. An examination of data reveals there is also great variation in respect of availability of electricity in Haryana. There are 13 districts in Haryana which has recorded electricity as main source of lighting above the state average $(90.5 \%)$ during Census 2011. It is noticed that high percentage of usage of electricity as a main source of lighting is recorded in Ambala (95.9\%), followed by Kurukshetra (95.8\%), Yamunanagar (95.3\%) and Gurgaon (95.3\%). The lowest percentage recorded in districts of Mewat (61.3\%), Palwal (79\%), Mahendergarh (80.3\%) and Bhiwani (86.2\%). The analysis of the Figure 1 exhibits that availability of electricity for population who are living in the western side of state i.e, Sirsa, Fatehabad, Hisar and Bhiwani experienced lower accessibility of electricity in comparison to eastern side of the Haryana. 


\section{Availability and Types of Latrine Facility:-}

The Census 2011 reveals that only 32,37,942households (68.6\%) of the total households in Haryana have latrine facility within the premises. As per Census 2011 , there are $31.4 \%$ of households having no latrine facility within the premises as compared to $53.1 \%$ of the country. In rural areas, there are $43.9 \%$ of households having no latrine facility within the premises whereas in urban areas of Haryana only $10.1 \%$ of households having no latrine within the premises. According to Census 2011, the concentration of households having water closet type of latrine facility within the premises is observed in the eastern districts. The highest percentage share is notices in Gurgaon (74\%), Faridabad (69\%), Panipat (64.7\%), Panchkula (63.2\%) and Rohtak (62.1\%). The lowest percentages are reported in the districts of Mewat (14.6\%), Fatehabad (24.9\%), Sirsa (25.7\%), Kaithal (28.7\%) and Mahendergarh (29\%)

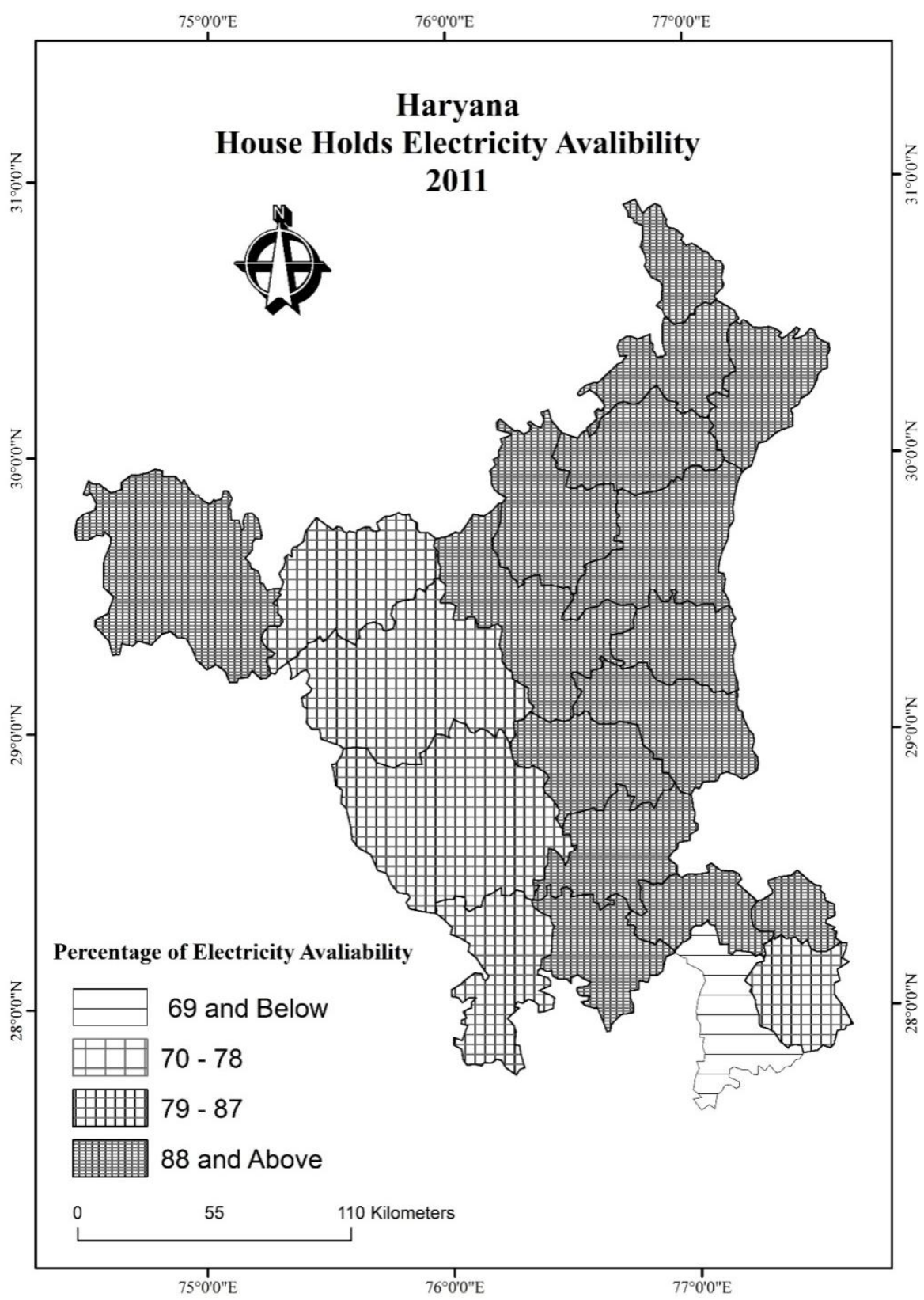




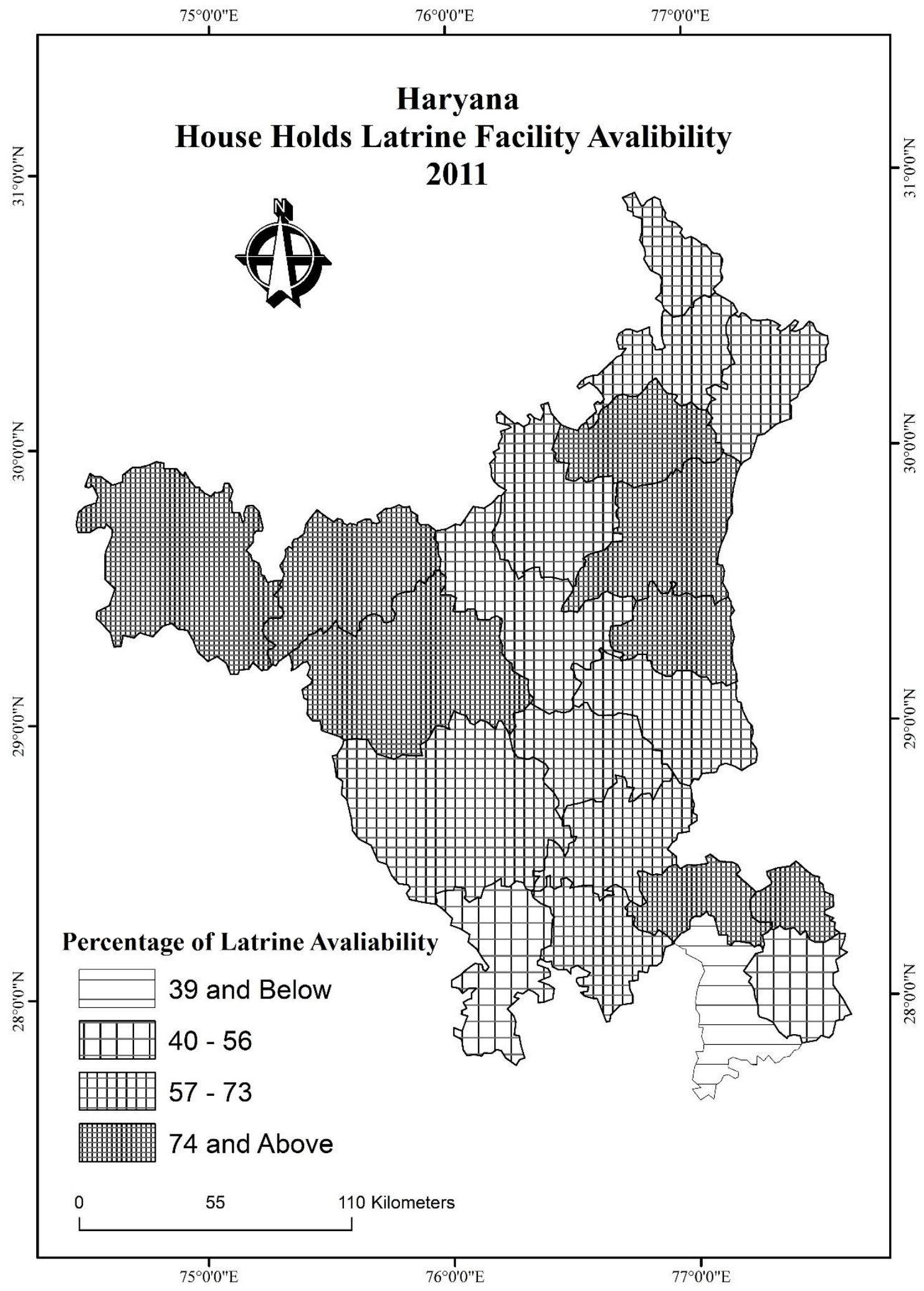




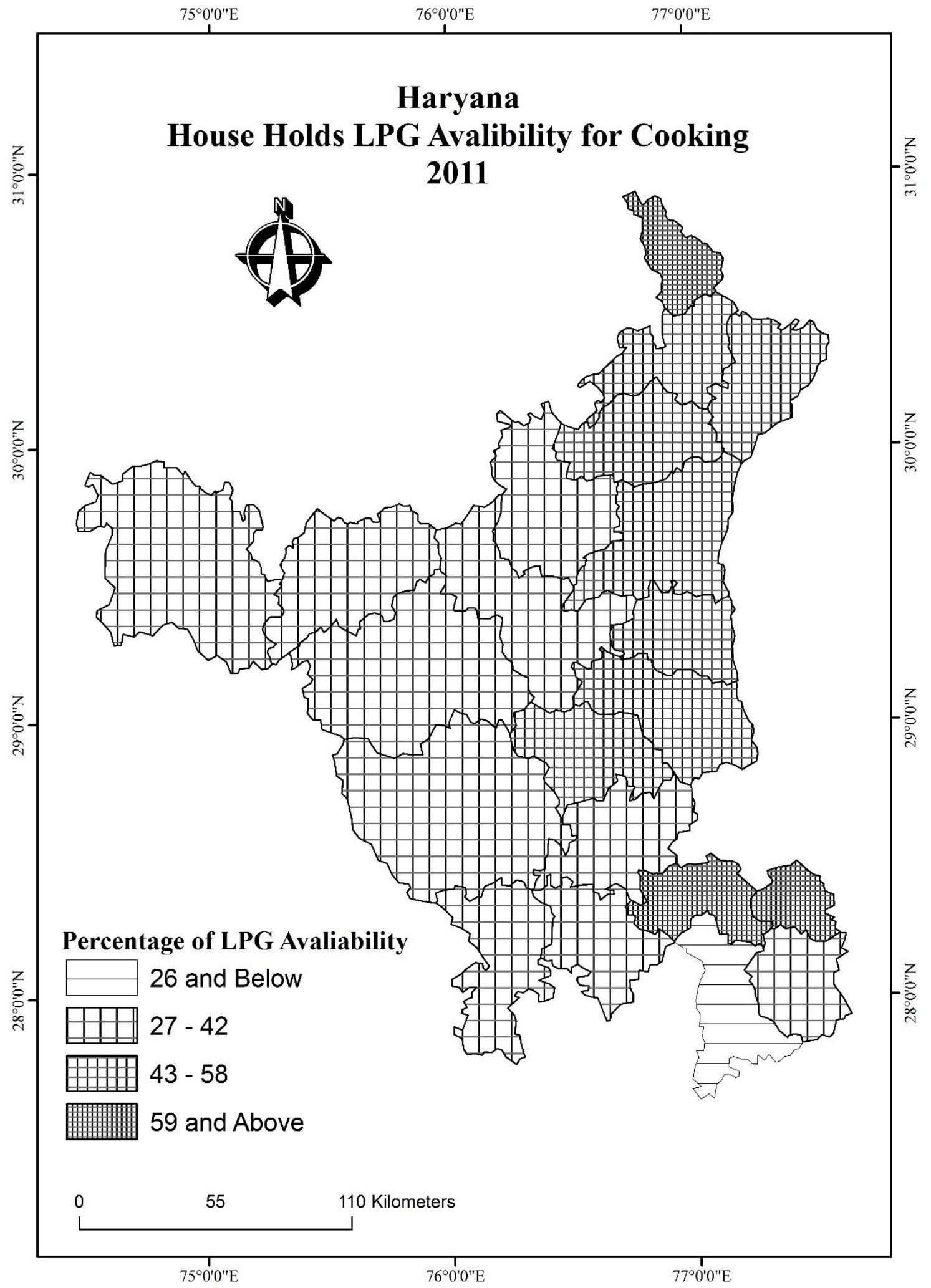

Fuelavailability:-

Main source of cooking In India, as identified by Census 2011 is classified as Firewood, Crop residue, Cow dung cake, Coal, Lignite, Charcoal, Kerosene, LPG/PNG, Electricity, Biogas, any other and no cooking. In Haryana, only $44 \%$ of households are using LPG for cooking. 
There are $26.6 \%$ of households are still using Firewood as fuel of cooking in Haryana. The other fuelused by households are Crop residue (14.1\%), Cowding Cake (14.2\%), Kerosene (1\%) and Bio gas $(0.25 \%)$. There are 54.3 $\%$ of the households are still using traditional fuel of cooking i.e. firewood,crop residue and cow dung cake.

During Census 2011, there are 12 districts of Haryana have recorded Firewood as fuel for cooking which is above the state average of $26.3 \%$. But all the district of Haryana has recorded below nation average of 49 percent. Among the districts, the maximum usage is registered in Mewat (47.8\%) followed by Bhiwani (43.6\%), Palwal (39.1\%) and Hisar (33.5\%). Households in 10 districts use LPG/PNG above the state average of $44 \%$. The highest percentage of households (74.3\%) using LPG/PNG as fuel of cooking is recorded in Gurgaon followed by Faridabad (73.2\%), Panchkula (63.2\%) and Ambala (58.5\%). Use of kerosene as fuel of cooking is very low in Haryana (1\%) and only 6 districts have recorded above the state average. Panchkula has registered the highest percentage $(5.2 \%)$ and the minimum which are negligible is recorded in Mewat.

\section{Conclusion:-}

Housing amenities such as access to electricity, a clean water supply, and the quality of fuels for cooking are major factors in determining the quality of life for population. The availability of these services and the number of household assets vary considerably throughout the Haryana. There are remarkable positive changes between 2001 and 2011 census. The study shows that the availability of tapas main source of drinking water decreases from high in the northern part to low in the Southern part ofthe state. There is a declining trend in availability of electricity from east to west direction. There is remarkable progress in toilet facilities within the premises of household from 2001 to 2011 census. Except some districts in southern part of the state, the general condition of latrine facilities is good in Haryana. There is a more than 50\% household using LPG in eastern side of the state but lower consumption have shown in western side of the state.

The GIS mapping gives us a spatial understanding of states and concluded that the level of housing status and condition is very high to high in the eastern part, while it is comparatively low level in the western parts of Haryana.

\section{References:-}

1. Census of India, Primary Census Abstract, Total Population, Series-1, Table A-5, Ministry of Dreze, I. and M. Murthi, Fertility, Education and Development: Evidence from India, Populationand Development Review, Vol. 27, No. 1, pp. 33-63. 2001.

2. Gupta, I. and A. Mitra , Basic Amenities and Health in Urban India, National Medical Journal ofIndia, Vol. 15, No. 4, pp. 242-244. 2002.

3. Hassan, Tarique and Khan, Dr.Jabir Hassan "Patterns of Availability of Housing and HouseholdAmenities in Odisha," Journal of Business Management \& Social Sciences Research(JBM\&SSR) volume 2, No.4, April 2013.

4. Hingorani, Pritika and Tiwari, Dr.Piyush "Housing and Basic Infrastructure services for all: Aconceptual framework for urban India", 2004.

5. Nayar, K. R., Housing Amenities and Health Improvement: Some Findings, Economic and Political Weekly, Vol. 32, No. 22 (May 31 - Jun. 6, 1997), pp. 1275-1279. 1997.

6. S. Mitra "Housing scenario in Odisha, Odisha Review, Census Special, 2001.

7. Shaw, A., Basic Amenities in Urban India: Analysis at State and Town Level, Indian Institute ofManagement Calcutta, WPS No. 616.

8. Smith, D.M. (1973) The Geography of Social Well-Being in the United States, McGraw-Hill, New York, pp. 71-85.

9. Srinivasan, K. and Mohanty, S.K "Household deprivation and its linkages with ReproductiveHealth Utilisation, "Economic weekly, volume 43, no.48, November 29 - December 5, 2008. 